\title{
Characterization of Five Molecular Markers for Pathotype Identification of the Clubroot Pathogen Plasmodiophora brassicae
}

\author{
Jing Zheng, Xuliang Wang, Qian Li, Shu Yuan, Shiqing Wei, Xiyu Tian, Yun Huang, Wenming Wang, and Hui Yang $\dagger$
}

First, second, third, fifth, sixth, seventh, and ninth authors: College of Agronomy; fourth author: College of Resources; and eighth author: Rice Research Institute and Research Center for Major Crop Diseases, Sichuan Agricultural University Chengdu Campus, Chengdu 611130, China. Accepted for publication 9 July 2018.

\begin{abstract}
Clubroot disease is an important disease on cruciferous crops caused by Plasmodiophora brassicae infections. The pathotypes have been classified based on the reactions of differential hosts. However, molecular markers of particular pathotypes for P. brassicae are limited. In this study, we found five genetic markers in association with different pathotypes. Different gene expression patterns among different pathotypes (P4, P7, P9, and P11) were assayed according to the transcriptome data. The assay

indicated that molecular markers PBRA_007750 and PBRA_009348 could be used to distinguish P11 from P4, P7, and P9; PBRA_009348 and Novel342 could distinguish P9 from P4, P7, and P11; and PBRA_008439 and Novel342 could represent a kind of $\mathrm{P} 4$. Polymerase chain reaction cycles ranging from 25 to 30 were able to identify the predominant pathotype in general. Therefore, these molecular markers would be a valuable tool to identify and discriminate pathotypes in $P$. brassicae population.
\end{abstract}

Clubroot disease is an important disease on cruciferous crops and is caused by Plasmodiophora brassicae Woronin infections. It is a soilborne, obligate, and biotrophic pathogen that leads to a subsequent reduction in the crop yield (Crisp et al. 1989; Dixon 2009). The disease is spreading rapidly in Asia and has become a problem not only in China, Japan, and Korea but also in tropical countries such as Indonesia, Thailand, and Vietnam (Dixon 2009). Now it is known to occur in more than 60 countries (Dixon 2009). In China, clubroot disease occurred in many provinces and caused serious damages to crucifer crops, and more than 20 public institutions have been making efforts to control clubroot disease (Chai et al. 2014).

However, clubroot disease is difficult to be controlled by either chemical or cultural means. Many strategies have been proposed; among them, the development of resistant cultivars is believed to be the most effective and environmentally friendly method. Breeding for a resistant cultivar requires a good understanding of the virulence pattern from the pathogen population. However, P. brassicae is so variable that a satisfactory method for detecting specific virulent isolates is still lacking. To learn more about identification of $P$. brassicae pathotypes and accelerate the breeding of clubrootresistant crops, Shen et al. (2009) identified clubroot pathogens from 15 major areas in China (including Liaoning, Jilin, Shandong, and Sichuan Provinces) and discovered that P4 was the predominant pathotype in 11 areas.

A specific isolate of $P$. brassicae could not be distinguished from others by phenotypic characteristics, except for virulence. Therefore, the pathotypes are usually identified based on their impacts on different hosts (Buczacki et al. 1975; Kuginuki et al. 1999; Williams 1966). The Williams differential system is the earliest one, and is used formally in wide applications (Williams 1966). Theoretically, by using four differential hosts, 16 physiological races can be identified. Buczacki et al. (1975)

†Corresponding author: Hui Yang; E-mail: yanghui981@126.com

*The $\boldsymbol{e}$-Xtra logo stands for "electronic extra" and indicates that one supplementary figure and two supplementary tables are published online.

(c) 2018 The American Phytopathological Society established the European clubroot differential (ECD) set, which is a currently universal identification system for clubroot pathogens in Europe. Both the Williams differential system and ECD are considered to be international identification systems and have been generally applied.

However, these identification systems also have some limits. For example, the maturity level of spores can influence the pathogenicity and further affect the accuracy of pathotype identification. Pathotype differentiation via virulence tests on a differential host generally takes as long as 2 months and is time consuming and labor intensive. Moreover, during a long growing period, environmental conditions and other uncertain factors may also affect the accuracy of identification (Sharma et al. 2011). Notably, the interpretation of results is sometimes confusing because of the nonhomogeneous reactions owing to the heterogeneity of $P$. brassicae in field (Crute and Pink 1989). Therefore, classifying $P$. brassicae into physiological races at the molecular level is a pertinent research trend. Specific molecular markers in association with the pathotypes would be a valuable tool for the identification and monitoring of $P$. brassicae populations. Previously, some random amplified polymorphic DNA (RAPD) markers have been developed and applied in pathogen polymorphism analysis (Buhariwalla et al. 1995; Ito et al.1997; Manzanares-Dauleux et al. 2000; Möller and Harling 1996; Yano et al.1997). ManzanaresDauleux et al. (2000) obtained a RAPD marker, OPL14 1200 , which is specific in pathotype 1 of $P$. brassicae, as classified by the method of Somé et al. (1996). Zhang et al. (2015) indicated that one gene, designated $\mathrm{Cr} 811$, was found to be exclusively present in pathotype P5. $C r 811$ could distinguish pathotype 5 from pathotypes 3 and 8 according to the Williams differential set (Zhang et al. 2015). These reports showed that molecular markers could be suitable to distinguish pathotypes (Faggian et al. 1999; Klewer et al. 2001). Establishing a molecular identification system of $P$. brassicae pathotypes will be key for increasing the breeding efficiency for disease-resistant cruciferous varieties and realizing a better control of clubroot disease.

Based on current knowledge, the molecular determinants of pathotypes are most related to the presence or absence or differential expression of marker genes. Transcriptome sequencing data are a good resource for marker gene screening. In this study, 
transcriptome data of $P$. brassicae in Brassica rapa at different days postinoculation were analyzed. The differential gene expression patterns between pathotypes 4 and 7 were focused and further used to screen molecular markers to particular pathotypes. We hypothesized that part of these genes may be specific to certain pathotypes. The objective of this study was to identify genes that were present in certain pathotypes. The primer pairs specific to these genes were first used to evaluate the presence of corresponding genes in genomic DNA samples obtained from different pathotypes. Then, we tested the applicability of these genes as molecular makers to differentiate unknown pathotypes.

\section{MATERIALS AND METHODS}

Preparation of resting spore suspension. For preparation of plant inoculation, $P$. brassicae resting spores were prepared as previously described (Ji et al. 2014). Root galls were homogenized using $10 \%(\mathrm{wt} / \mathrm{vol})$ sucrose in a blender. The slurry was filtered through eight layers of gauze and the suspension was clarified by centrifugation at 3,000 rpm for $9 \mathrm{~min}$. The pellet was suspended in sterile water and transferred into a new tube containing $40 \mathrm{ml}$ of water. After centrifugation at 4,000 rpm for $12 \mathrm{~min}$, the resting spore precipitate was resuspended in sterile water, adjusted to a concentration of $1 \times 10^{7}$ spores $/ \mathrm{ml}$, and stored at $4^{\circ} \mathrm{C}$. For pathotype determination on the Williams differential hosts, 30 seedlings of each host line were inoculated with each field isolate of $P$. brassicae. These steps were repeated three times.

Plant inoculation with $\boldsymbol{P}$. brassicae. For transcriptome sequencing and semiquantitative reverse-transcription polymerase chain reaction (RT-PCR) analysis, B. rapa seedlings were inoculated with a $600-\mu l$ suspension of $P$. brassicae resting spores with a density of $10^{7}$ spores $/ \mathrm{ml}$. The inoculated plants were maintained in a growth chamber under $16 \mathrm{~h}$ of light at $25^{\circ} \mathrm{C}$ and the soil was kept moist during the treatment period. The root of Chinese cabbage was obtained at $4,10,16$, and 45 days postinoculation (dpi) and washed thoroughly with distilled water to remove the spores adsorbed on the surface, then frozen in liquid nitrogen and stored at $-70^{\circ} \mathrm{C}$.

$B$. rapa with $P$. brassicae inoculations and transcriptome sequencing. According to the previous identification results by Williams's system, isolates DY and LX were identified as pathotype 4 and pathotype 7 , respectively. In this experiment, B. rapa (Chinese cabbage cultivar Zaoshu-5) (San Duo Seed) seedlings were inoculated with suspensions of P. brassicae P4 (DY) and P7 (LX), respectively. The total RNA of clubroot was extracted and sent to Novogene Biotechnology Company for sequencing. The differential expression of genes between P4 (DY) and P7 (LX) was analyzed basing on the transcriptome data. Genes with higher expression levels in the P4 (DY) sample than the P7 (LX) sample were selected for further identification. Finally, five molecular markers were screened out. The read counts of genes in different samples and annotations are listed in Supplementary Table S1.

Screening of primers and specificity analysis. Chinese cabbage (Zaoshu-5) was used as the host to maintain P. brassicae spores. Isolates LX and KD were classified as pathotype 7 (P7). DY, SL, LJ, and FL were the P4 pathotype according to the system of

TABLE 1. Plasmodiophora brassicae isolates used for gene screening

\begin{tabular}{lllc}
\hline $\begin{array}{l}\text { Isolate name } \\
\text { or number }\end{array}$ & \multicolumn{1}{c}{ Collection site } & \multicolumn{1}{c}{ Host origin } & Pathotype \\
\hline KD & Kangding, Ganzi & Rape & 7 \\
LX & Lixian, Aba & Chinese cabbage & 7 \\
DY & Dayi, Chengdu & Rape & 4 \\
SL & Shuangliu, Chengdu & Rape & 4 \\
LJ & Luojiang, Deyang & Green vegetables & 4 \\
FL & Fuling, Chongqing & Mustard & 4 \\
\hline
\end{tabular}

Williams (Table 1). The total DNA of root gall samples, including root and resting spores, were used for the identification of pathotypespecific genes. Finally, five pathotype-specific genes were obtained. The sequences of primers are listed in Table 2. Two pairs of primers for each gene were designed according to the nucleotide sequences. The fragment was aligned with the transcriptome sequence data to ensure the presence of intron (Fig. 1), and the BLAST result is listed in Table 3.

In total, 40 field isolates (Supplementary Table S2) of $P$. brassicae derived from the host galls caused by natural infections were collected in China (mainly in Sichuan Province). Pathotypes were classified according to the system of Williams. The resting spores of $P$. brassicae were collected from root galls of different crucifer hosts; then, DNA of resting spores was subjected to PCR analysis with pathotype-specific genes.

All PCR analyses were run in a final volume of $10 \mu \mathrm{l}: 5 \mu \mathrm{l}$ of $2 \times$ Taq Master Mix (Takara), $0.5 \mu \mathrm{l}$ of each primer, and $0.5 \mu \mathrm{l}$ of DNA template. The concentration of DNA was approximately 200 to $300 \mathrm{ng}$. PCR was performed, and the first amplification cycle consisted of denaturation at $94^{\circ} \mathrm{C}$ for $2 \mathrm{~min} ; 30$ cycles of $94^{\circ} \mathrm{C}$ for $30 \mathrm{~s}$ (denaturation), $55^{\circ} \mathrm{C}$ for $60 \mathrm{~s}$ (annealing), and $72^{\circ} \mathrm{C}$ for $1 \mathrm{~min}$ (extension); and a final extension at $72^{\circ} \mathrm{C}$ for $7 \mathrm{~min}$. Here 25,30 , and 35 cycles were used for analysis of the best amplification results, respectively.

To determine whether the host could affect primer specificity, we mixed DNA of $P$. brassicae with DNA of eight usual hosts. The crucifer cultivars included $B$. rapa pekinensis, Raphanus sativus L., B. chinensis var. chinensis, B. napus L., B. juncea (L.) Czern. et Coss., B. oleracea L., B. oleracea L. var. botrytis L. and B. rapa L. subsp. chinensis.

DNA extraction from $P$. brassicae resting spores. The resting spores were washed five times in sterile distilled water, dispersed in $100 \mathrm{mM} \mathrm{MgCl} 2$ and $200 \mathrm{mM}$ Tris (pH 7.4) buffer, and treated with DNase I $(30 \mu \mathrm{g} / \mathrm{ml})$ for $3 \mathrm{~h}$ at $37^{\circ} \mathrm{C}$ to eliminate host DNA. The solution was centrifuged at $2,500 \times g$ for $5 \mathrm{~min}$, and the pellet was incubated for $30 \mathrm{~min}$ at $37^{\circ} \mathrm{C}$ in $5 \mathrm{mM}$ EDTA, $0.5 \%$ sodium dodecyl sulfate, and $10 \mathrm{mM}$ Tris $(\mathrm{pH} 7.8)$ containing proteinase $\mathrm{K}$ at $20 \mu \mathrm{g} / \mathrm{ml}$. The sample was then centrifuged at 4,000 rpm for $10 \mathrm{~min}$, the supernatant was discarded, and the resting spores were frozen in liquid nitrogen and stored $-70^{\circ} \mathrm{C}$.

$P$. brassicae DNA was extracted from the above prepared resting spores by cetyltrimethylammonium bromide (CTAB). DNA of root galls, including plant tissue and resting spores, was also extracted by CTAB. The samples were ground by first freezing in liquid

TABLE 2. Sequence of primers used in this study

\begin{tabular}{llcc}
\hline & \multicolumn{1}{c}{ Sequence $\left(5^{\prime}-3^{\prime}\right)$} & $\begin{array}{c}\text { Annealing } \\
\text { temperature/ }\end{array}$ & \\
Primer & Size (bp) \\
\hline Novel342-1-F & TCCTCTTGAACCGACACTGC & 57 & 249 \\
Novel342-1-R & CTTCTCTCGCACTAGCCAGG & $\ldots$ & $\ldots$ \\
Novel342-2-F & CCACGCCTATACCCGGAAAG & 57 & 666 \\
Novel342-2-R & CAACAGGACGGCGTTGAAAG & $\ldots$ & $\ldots$ \\
Novel407-1-F & ATTGCGTTGCTGAACTGCTG & 54 & 549 \\
Novel407-1-R & GTGCCCAATAGCAATCGCAG & $\ldots$ & $\ldots$ \\
Novel407-2-F & GTCGTTGTTCGGGGAGAAGT & 57 & 683 \\
Novel407-2-R & GTCCATAGGTGTGGGAACGG & $\ldots$ & $\ldots$ \\
PBRA_007750-1-F & CTTCGTGCTGACCGATTCCT & 57 & 638 \\
PBRA_007750-1-R & ATAATGCTCTGCGTCAGCCA & $\ldots$ & $\ldots$ \\
PBRA_007750-2-F & ATCTGTTCGATTCGCCTGCT & 57 & 1,034 \\
PBRA_007750-2-R & GAGTGTACAGGCTCGCTCAG & $\ldots$ & $\ldots$ \\
PBRA_008439-1-F & TCGGCGACCTGAGCGAGAA & 57 & 651 \\
PBRA_008439-1-R & TCAACATGCGCATAGTAC & $\ldots$ & $\ldots$ \\
PBRA_008439-2-F & TCGAGGTATCGCAGTCGAC & 60 & 367 \\
PBRA_008439-2-R & GATCTCCAGTGACGAGCCGT & $\ldots$ & $\ldots$ \\
PBRA_009348-1-F & CACTGCTATCGTCTCCCTGG & 54 & 509 \\
PBRA_009348-1-R & CCTGCAATGTTTCGCTGCAA & $\ldots$ & $\ldots$ \\
PBRA_009348-2-F & CCTTGCCCTGGTATTCGTCA & 54 & 260 \\
PBRA_009348-2-R & CAACGACAACGACCAAACCG & $\ldots$ & $\ldots$ \\
Actin-F & GGGACATCACCGACTACCTG & 54 & 160 \\
Actin-R & ACTGCTCCGAGTTGGACATC & $\ldots$ & $\ldots$ \\
\hline & & & \\
\hline
\end{tabular}


nitrogen before extraction. Then, the powder was transferred into a 2 -ml centrifuge tube, $700 \mu \mathrm{l}$ of $2 \times$ CTAB ( $2 \%$ CTAB, $100 \mathrm{mM}$ Tris$\mathrm{HCl}$ [PH 8.0], $20 \mathrm{mM}$ EDTA, and $1.4 \mathrm{M} \mathrm{NaCl}$ ) was added, and samples were mixed by inversion or gentle shaking and stored at $65^{\circ} \mathrm{C}$ for $1 \mathrm{~h}$. Following centrifugation at $12,000 \times g$ for $15 \mathrm{~min}$, the supernatant was transferred to a fresh tube. This step removed insoluble tissue fragments from the lysate. Then, an equal volume of phenol-chloroform-isoamyl alcohol (25:24:1) was added and centrifuged at $12,000 \times g$ for $15 \mathrm{~min}$. The suspension was transferred into a $2-\mathrm{ml}$ centrifuge tube. DNA was precipitated from the lysate by the addition of $1 \mathrm{ml}$ of $100 \%$ ethanol per $0.5 \mathrm{ml}$ used for the isolation, stored at $-70^{\circ} \mathrm{C}$ for at least $1 \mathrm{~h}$, then centrifugated at $12,000 \times g$ for $15 \mathrm{~min}$ at room temperature. The DNA precipitate was washed twice with $1 \mathrm{ml}$ of $75 \%$ ethanol. At each wash, the DNA was suspended in ethanol by inverting the tubes three to six times. DNA was air dried by storing in an open tube after removing the ethanol. Then, DNA was solubilized in double-distilled $\mathrm{H}_{2} \mathrm{O}$ and stored at $-20^{\circ} \mathrm{C}$.

Gene expression verify by semiquantitative RT-PCR. In this experiment, the Chinese cabbage cultivar Zaoshu-5 and P. brassicae isolate LJ (P4) were used. Total RNA of root samples was extracted by using TRIpure Reagent (Aidlab Biotech), according to the manufacturer's instructions. For cDNA synthesis, 3 to $5 \mu \mathrm{g}$ of total RNA and the M_MLV RT (Takara) was used according to the manufacturer's instructions. For the semiquantitative expression analysis, the $P$. brassicae actinl gene was used as the reference.

\section{RESULTS}

Five molecular markers could distinguish P4 from P7. DNA of $P$. brassicae was extracted from young roots of $B$. rapa; then, the mixture of host and parasite DNA was subjected to PCR.

TABLE 3. Alignment results of different markers ${ }^{\mathrm{a}}$

\begin{tabular}{lccc}
\hline & & \multicolumn{2}{c}{$\begin{array}{c}\text { dentity (\%) of polymerase chain } \\
\text { reaction fragment with }\end{array}$} \\
\cline { 3 - 4 } Marker name & Size (bp) & $\begin{array}{c}\text { Transcriptome } \\
\text { data }\end{array}$ & $\begin{array}{c}\text { Sequence of } \\
\text { Plasmodiophora brassicae } \\
\text { pbe3.h15 genome }\end{array}$ \\
\hline Novel342-2 & 666 & 89.39 & $\ldots$ \\
Novel407-2 & 683 & 91.54 & $\ldots$ \\
PBRA_007750-2 & 1,034 & 100 & 100 \\
PBRA_008439-1 & 651 & 100 & 100 \\
PBRA_009348-1 & 509 & 100 & $\ldots$
\end{tabular}

a The larger amplicon of each gene was sequenced for the verification. Markers Novel342 and Novel 407 were aligned with the sequence of transcriptome data by using DNAMAN. Markers with names beginning "PBRA" were aligned with the sequence of GenBank and transcriptome data.
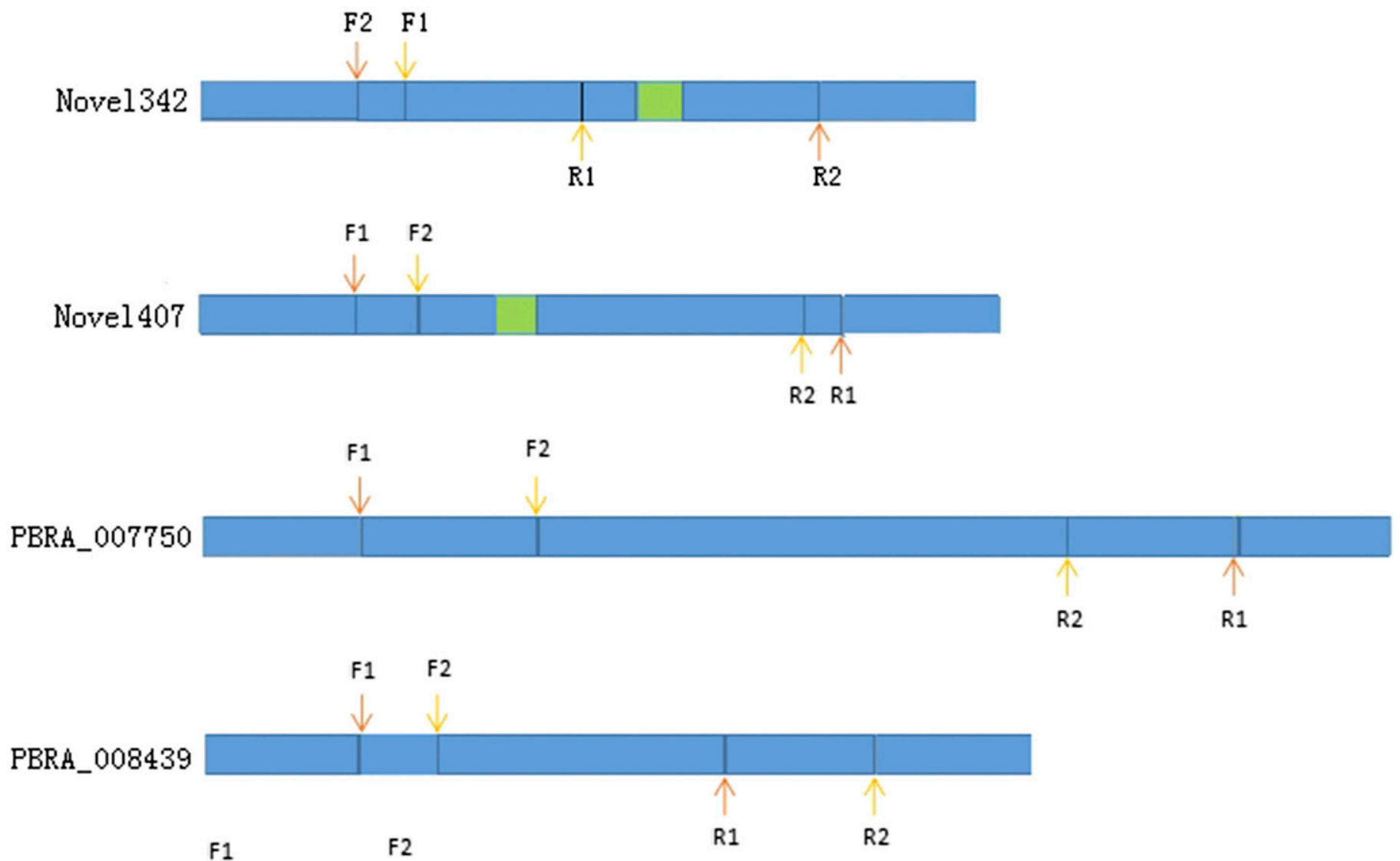

PBRA_009348

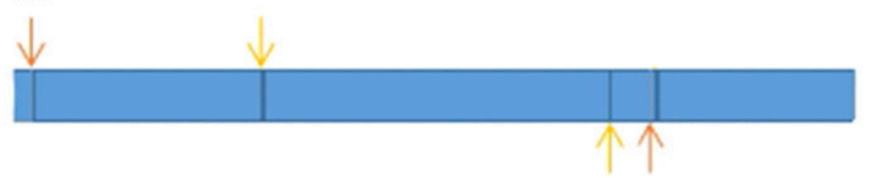

R2R1

Fig. 1. Diagram of genomic regions of Novel342, Novel407, PBRA_007750, PBRA_008439, and PBRA_009348. Lighter segments refer to intron and darker to exon. We blasted polymerase chain reaction product with transcriptome data to ensure that the gene fragment has introns. 
The housekeeping gene actinl was used as the control (Supplementary Fig. S1). Among selected genes, five molecular markers were finally screened out for further analysis. The sequences of PCR fragments of PBRA_007750, PBRA_008439, and PBRA_009348 had $100 \%$ identity with those in the P. brassicae genome pbe3.h1 in the National Center for Biotechnology Information (NCBI) website. The query covers of Novel342 and Novel407 had less than $6 \%$ identity with the sequences in the NCBI website. The sequences of PCR fragments of Novel342 and Novel 407 had 89.39 and $91.54 \%$ identity with the transcriptome sequence and were located in CDSF01000088.1 and CDSF01000096.1 chromosome fragments, respectively.

The primer pairs of five molecular markers, including Novel342, Novel407, PBRA_007750, PBRA_008439, and PBRA_009348, amplified the expected size of amplicons from P4 (isolates DY, LJ, and SL) but not from P7 (KD and LX isolates). Thus, Novel342, Novel407, PBRA_007750, PBRA_008439, and PBRA_009348 could distinguish $\mathrm{P} 4$ from $\mathrm{P} 7$ among the tested samples. The expected fragments could be amplified with the primer pairs of Novel342 or Novel407 but not with the primer pairs of PBRA_007750, PBRA_008439, or PBRA_009348 in isolate FL (P4). This means that $\mathrm{P} 4$ of $P$. brassicae could be distinguished by two molecular markers. The primer pairs of Novel407 especially produced a nontarget fragment (approximately 1,200 bp in size) from P7 (KD and LX isolates). To ensure the stability of PCR results, another primer pair of each gene was designed. Amplicons of expected size were also obtained, which were consistent with the above PCR assay (Fig. 2).

Analysis of primer specificities affected by different hosts. The intracellular life cycle of the pathogen suggests that plasmodia DNA was strongly contaminated by the host DNA. Although spores of the pathogen could be isolated free of host cell materials, contamination of host DNA could still be found in the spores. Therefore, we wanted to test whether the other host tissues could influence the PCR results. The DY isolate (P4) and LX isolate (P7) DNA and DNA of eight different hosts were mixed, then subjected for PCR identification. The primers of Novel342, Novel407, PBRA_007750,PBRA_008439, and PBRA_009348 could specifically amplify the target fragment from the DNA mixture of DY isolates with nine different hosts but did not produce any result or amplicons of expected size from the DNA mixture of LX isolates with nine different hosts. The results indicated that the primer specificity of five molecular markers could not be affected by the host's DNA (Fig. 3).

Five molecular markers distinguished field isolates of different pathotypes. Forty field isolates were used to further analyze the specificity of five molecular markers. Galls were collected from different fields in China, mainly in Sichuan Province, selected based on previous identification results by members of our lab and other researchers. The pathotype identification of 40 isolates was first determined with the Williams differential hosts. The resting spores of 40 field isolates were collected from mature galls and evaluated by PCR analysis with each primer pair. Primer pairs of Novel342 and Novel407 could produce the expected size of amplicons with genomic DNA of P4 and P11 but not with P7 and P9 (Fig. 4), which indicated that the two molecular markers could distinguish P4 (isolates 1 to 4, 6 to 18,20 to 26,31 to 32, 34, 36, 38, and 40) from P7 (isolates 9, 19, 28, and 30) and P9 (isolates 37 and 39) but not P11 (isolates 27, 29, 33, and 35).

We found that all P4 isolates produced the expected size of amplicons with primer pairs of Novel342 and Novel407. However, only part of the $\mathrm{P} 4$ isolates produced the expected size of amplicons with primer pairs of PBRA_007750, PBRA_008439, and PBRA_009348. Because the expected fragments could be always amplified with primers of Novel342 and Novel407, whereas PBRA_008439 only worked for one P4 genotype but not the other genotypes of P4, P7, P9, and P11, the primer pairs of PBRA_008439 and Novel342 or PBRA_008439 and Novel407 should be used to differentiate the genotype of $\mathrm{P} 4$ from $\mathrm{P} 7, \mathrm{P} 9$, and P11 (Table 4).

We found that PBRA_007750 or PBRA_008439 could be specially detected in P11 and some genotypes of P4 but PBRA_009348 could not be detected in P11. Therefore, we suggested that, if the target fragment could be amplified with the primers of PBRA_007750 or PBRA008439 but not with PBRA009348, the pathotype should be P11 but not P4.

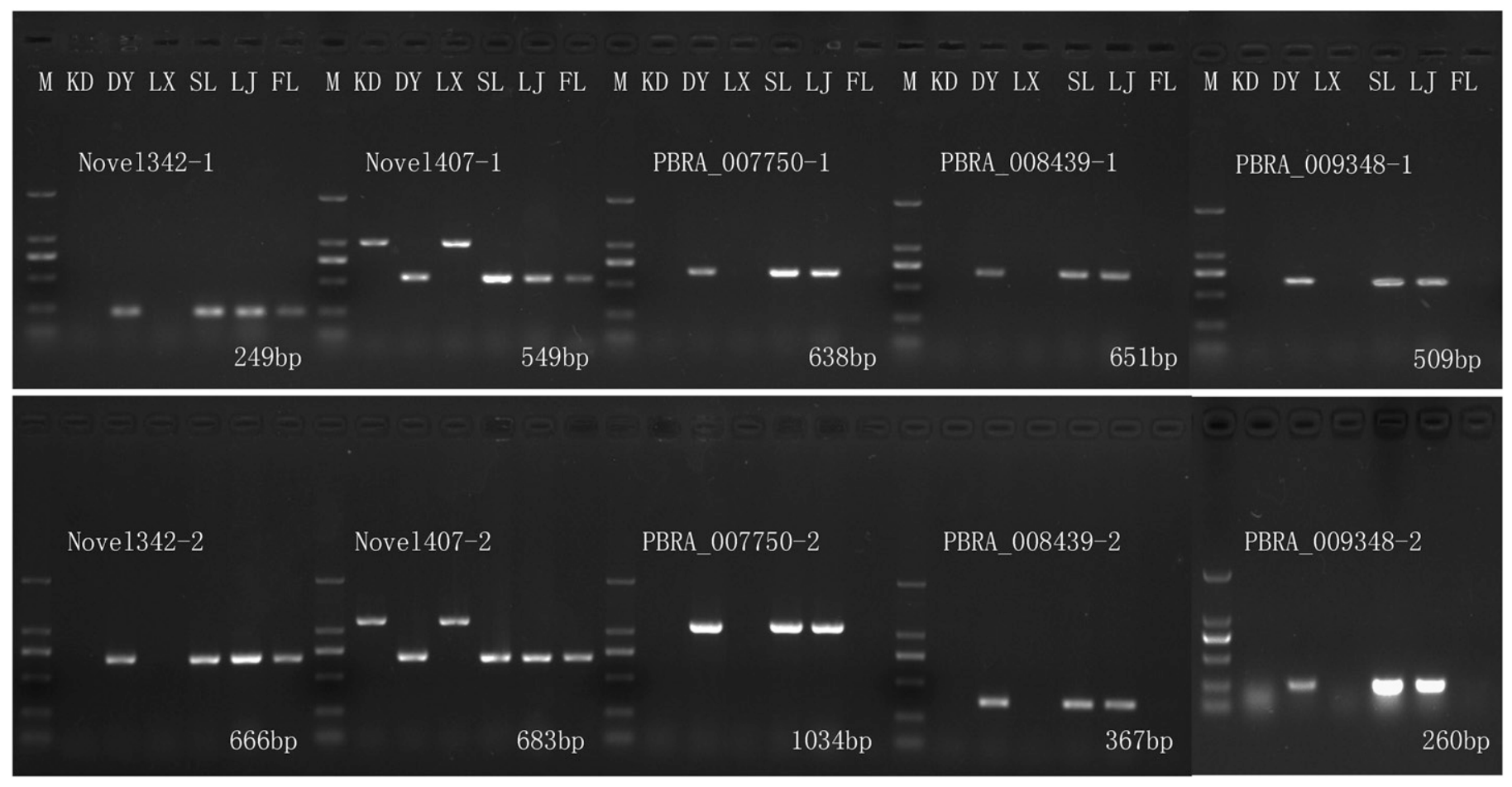

Fig. 2. Identification of the presence of Novel342, Novel407, PBRA_007750, PBRA_008439, and PBRA_009348 in pathotype 4 and pathotype 7 of Plasmodiophora brassicae. Lane M = DNA marker 2000; from top to bottom, the size of band was 2,000, 1,000, 750, 500, 250, and 100 bp, respectively. 
PBRA_009348 could be specially detected in P9 and some genotypes of P4. Neither Novel342 nor Novel407 amplified the expected fragments of $\mathrm{P} 9$, which indicated that PBRA_009348 and Novel342 or PBRA_009348 and Novel407 could be used to distinguish $\mathrm{P} 9$ from $\mathrm{P} 4$.

These results indicated that five molecular markers had a potential to distinguish pathotypes of $P$. brassicae. The pathotypes and genotypes of $P$. brassicae may be identified by one molecular marker or several molecular markers, which was summarized in Table 4

Effect of PCR cycles on the identification result. Different pathotypes, including dominant and rare races, might be present simultaneously in a single gall and a complicated result might be obtained. Therefore, three different PCR cycles $(25,30$, and 35 cycles) were used to test the presence of rare races or complicated results in root galls. We tested five genes of resting spores in nine field isolates. The $P$. brassicae actin gene was employed as the control gene, which could be detected after 25 PCR cycles. The target amplicons from the corresponding pathotypes were only obtained between 25 and 30 cycles. However, the target amplicons could be obtained in all isolates at 35 cycles, although the amplification levels were lower from noncorresponding pathotypes. The expected PCR fragments were more obvious in isolates $9,21,33$, and 35 than isolates $5,17,22,30$, and 37 with the primers of PBRA_008439 (Fig. 5). The result indicated that a mixture of different pathotypes surely existed in some clubroots and could be easily identified by PCR detection. Therefore, the optimal PCR cycles should be set between 25 and 30 cycles for the molecular identification of pathotypes to reduce false-positive results.

Expression of molecular markers in infected plants. RTPCR was analyzed at different time points $(4,10,16$, and $45 \mathrm{dpi})$ in Chinese cabbage with isolate DY infection. The expression levels of Novel 342 were visible at $4 \mathrm{dpi}$, increased at $10 \mathrm{dpi}$, and could not be observed at $16 \mathrm{dpi}$, but reached a peak at 45 dpi during symptom information period. For other molecular markers, including Novel407, PBRA_007750,PBRA_008439, and PBRA_009348, the expression level was hardly detected until they were obvious at 45 dpi (Fig. 6). This result was consistent with the transcriptome data and suggested that these genes might contribute to gall formation.

\section{DISCUSSION}

Pathotype classification of the isolates was always performed according to the disease symptoms of different hosts (Somé et al. 1996). However, the differentiating PCR markers and the molecular basis for classification of $P$. brassicae pathotypes are still limited. In this experiment, we focused on genes which expressed differently between four pathotypes of $P$. brassicae in transcriptome data. Novel342, Novel407, PBRA_007750,PBRA_008439, and PBRA_009348 were screened out as markers to identify $P$. brassicae pathotypes. Interestingly, Novel342 and Novel407 were not found in the P. brassicae pbe $3 . h 15$ genome (Schwelm et al. 2015), suggesting its absence in this strain. A notion accepted by most researchers is that the different pathotypes have an inner connection with their genetic makeups, such as the absence or presence of certain pathogenicity-related genes, or differential expression of those genes (Zhang et al. 2015). Among tested pathotypes P4, P7, P9, and P11, we found that Novel342, Novel407, PBRA_007750, PBRA_008439, and PBRA_009348 genes were present in $\mathrm{P} 4$ of $P$. brassicae but not in $\mathrm{P} 7$. To make more accurate identification of pathotypes, we suggest that the combination of two genes should be used to ensure a certain pathotype. Furthermore, we should notice that the same pathotype is usually present in different genotypes. For example, PBRA_007750, PBRA_008439, and PBRA_009348 detected two different genotypes of P4, indicating a potential method to identify new strains of $P$. brassicae.

The practicality of molecular markers was confirmed by using the field isolates in Sichuan Province. The results indicated that P4 was

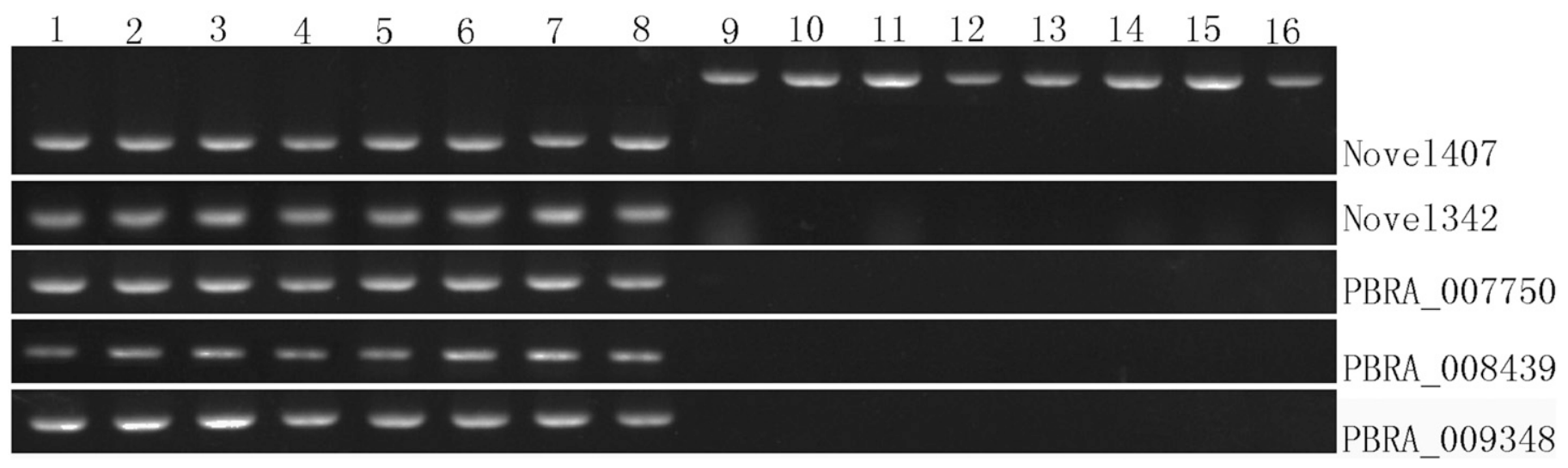

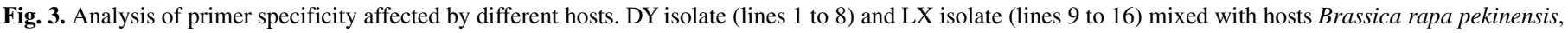

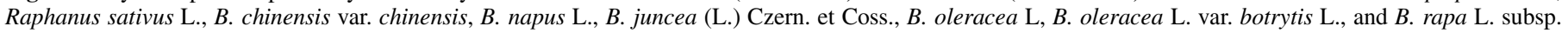
chinensis, respectively.

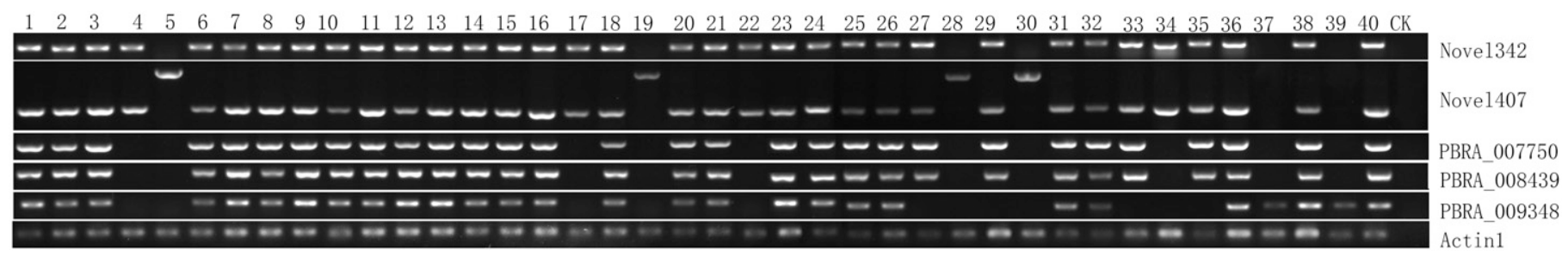

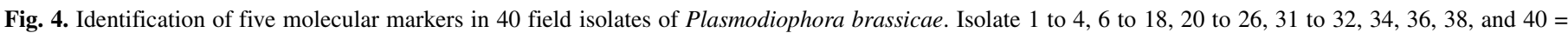

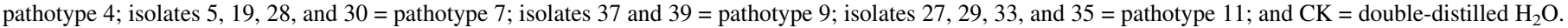
The $P$. brassicae gene actinl was used as a positive control of the existence of $P$. brassicae. 
the predominant race, and mainly distributed around the Chengdu plain. The Jialing River, Minjiang River, and Tuojiang River flow through Chengdu plain and might facilitate the long-distance spread of $P$. brassicae. P7 is mainly distributed in cool areas such as Xichang, Aba, and Kangding. These results were consistent with previous identification using the Williams system in our lab. Therefore, the PCR assay designed in this study could be a convenient tool for identifying and monitoring the distribution of $P$. brassicae pathotypes in Sichuan Province. This result should be further confirmed by testing on larger collections of isolates in broader geographical regions with more pathotypes.

Horizontal gene transfer (HGT) usually provides a means for pathogens to create new races or pathotypes (Mehrabi et al. 2011; Ochman et al. 2000). HGT is very common in protists. We suggested that $P$. brassicae may be an HGT-amiable species (Richards et al. 2003). The presence of a gene in a certain isolate but complete absence in some other isolates suggests that this gene may be a result of HGT. For example, we found that the two primer pairs of Novel407 could amplify 549- and 683-bp fragments from genomic DNA of P4 and P11, respectively, and two 1,100- and 1,200-bp nontarget fragments in P7. An approximately 200-bp nucleotide sequence in the nontarget fragments could be blasted with the transcriptome sequence of P4 (isolate DY) and genome of $P$. brassicae in the NCBI website, which means that an HGT might occur in $\mathrm{P} 7$.

The greatest important advantage is that the PCR method could be performed rapidly and directly from clubs without purification of resting spores. Host DNA would not affect the result; therefore, it may serve as a molecular marker to identify pathotypes with total DNA from a tiny gall. Because a mixture of different pathotypes might exist in a root nodule, as reported by Somé et al. (1996) and Kuginuki et al. (1999), it is not an ideal way to apply too many PCR cycles. An appropriate number of cycles would give optimal results. With the molecular markers, we could detect what kind of

TABLE 4. Identification of tested pathotypes by one molecular marker or several molecular markers

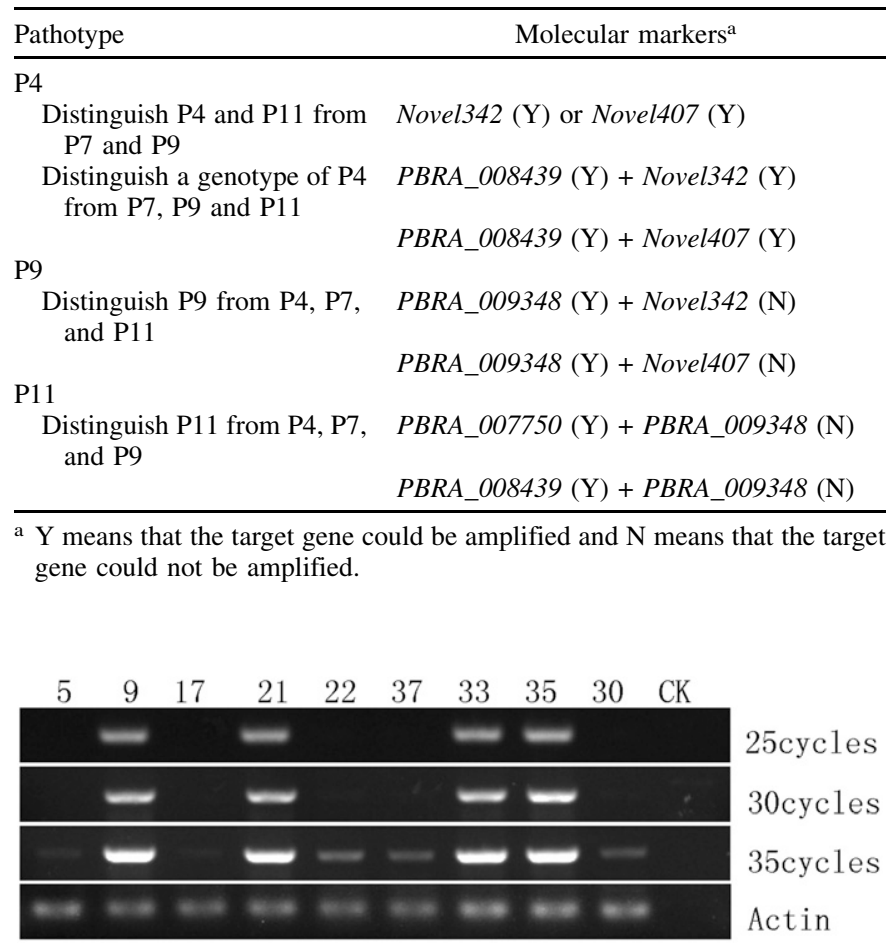

Fig. 5. Results of different polymerase chain reaction cycles for identification of pathotypes by PBRA_008439. Isolates 5 and $30=$ pathotype 7 ; isolates 9 , 17,21 , and $22=$ pathotype 4 ; isolate $37=$ pathotype 9 ; isolates 33 and $35=$ pathotype 11; and $\mathrm{CK}=$ double-distilled $\mathrm{H}_{2} \mathrm{O}$. pathotype may hold in a field and which pathotype is predominant. Also, the method is useful for $P$. brassicae-resistant cultivar breeding.

Among five molecular markers, the expression level of Novel342 was visible at early and late infection periods. However, its functions have not been annotated. We predicted the function on the SMART protein website (http://smart.embl-heidelberg.de/). The Novel342 protein was predicted with four domains, including CXC, ANATO, DEFSN, and CRAL_TRIO_N domains. Anaphyla toxin homologous (ANATO domain) $\mathrm{C} 3 \mathrm{a}, \overline{\mathrm{C}} 4 \mathrm{a}$, and $\mathrm{C} 5 \mathrm{a}$ anaphyla toxins are protein fragments generated enzymatically in serum during activation of complement molecules C3, C4, and C5. Complement components $\mathrm{C} 3, \mathrm{C} 4$, and $\mathrm{C} 5$ are large glycoproteins that have important functions in the immune response and host defense (Fritzinger et al. 1992). Defensins (DEFSN domain) are 2- to 6-kDa, cationic, microbicidal peptides active against many Gram-negative and Gram-positive bacteria, fungi, and enveloped viruses (White et al. 1995). PBRA_008439 was annotated, which includes an ankyrin repeat and SEC7 domain containing protein SecG. SecG translocates both periplasmic and outer membranes through the cytoplasmic membrane and is coassembled into lipids with SecA to yield highly active translocons (Sugai et al. 2007). Here, we suggest that PBRA_008439 might be related to translocation of defense proteins, especially in the late infection of $P$. brassicae. The roles of five molecular markers need to be further verified.

Selection of certain pathotypes by host plants has implications for agricultural practice, because the infection potential in a certain field is dependent on the cultivar varieties. New pathotypes may be generated by mutations in one or some key pathogenic genes and these processes may be accelerated in artificial cultivars. Molecular markers may be used to gain a better understanding of genetic variability. This set is also useful for studying the correlations among molecular markers, virulence, and recombination in a progeny. Establishing a molecular identification set needs less time and space than the traditional Williams identification system. Future studies may include a larger number of isolates which come from different hosts and geographic origins and add more markers to find more representative genes for different pathotypes.

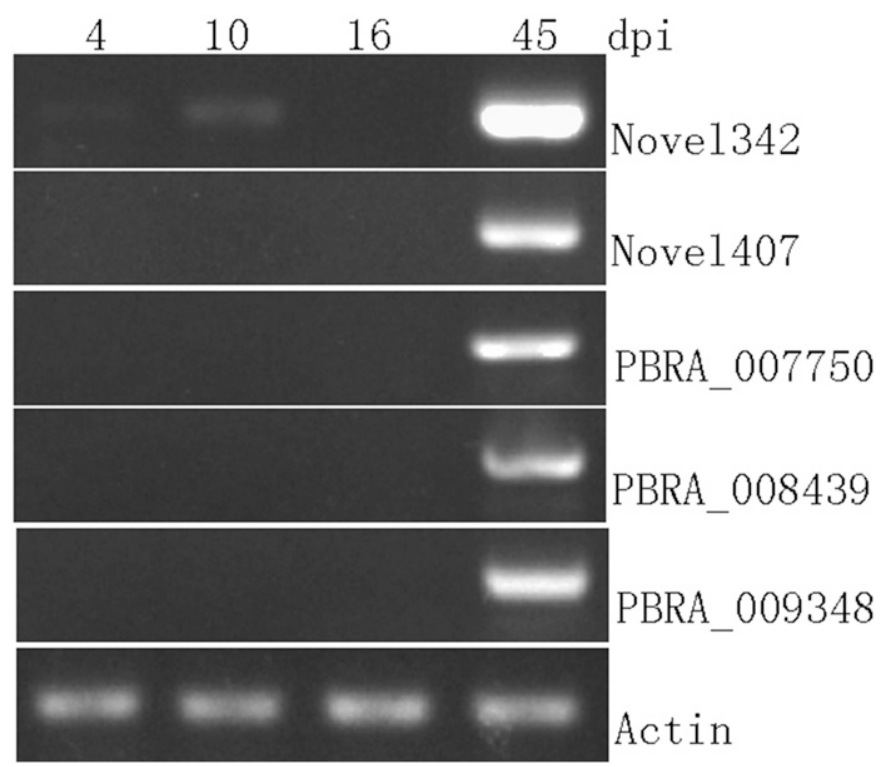

Fig. 6. Expression of Novel342, Novel407, PBRA_007750, PBRA_008439, and PBRA_009348 during the different infection periods. Plasmodiophora brassicae actin1 was used as the reference gene. 


\section{LITERATURE CITED}

Buczacki, S. T., Toxopeus, H., Mattusch, P., Johnston, T. D., Dixon, G. R., and Hobolth, L. A. 1975. Study of physiological specialization in Plasmodiophora brassicae: Proposals for attempted rationalization through an international approach. Trans. Br. Mycol. Soc. 65:295-303.

Buhariwalla, H., Greaves, S., Magrath, R., and Mithen, R. 1995. Development of specific PCR primers for amplification of polymorphic DNA from the obligate root pathogen Plasmodiophora brassicae. Physiol. Mol. Plant Pathol. 47:83-94.

Chai, A. L., Xie, X. W., Shi, Y. X., and Li, B. J. 2014. Research status of clubroot (Plasmodiophora brassicae) on cruciferous crops in China. Can. J. Plant Pathol. 36:142-153.

Crisp, P., Crute, I. R., Sutherland, R. A., Angell, S. M., Bloor, K., Burgess, H., and Gordon, P. L. 1989. The exploitation of genetic resources of Brassica oleracea in breeding for resistance to clubroot Plasmodiophora brassicae. Euphytica 42:215-226.

Crute, I. R., and Pink, D. A. C. 1989. The characteristics and inheritance of resistance to clubroot in Brassicae oleracea. Asp. Appl. Biol. 23:57-60.

Dixon, G. R. 2009. The occurrence and economic impact of Plasmodiophora brassicae and clubroot disease. J. Plant Growth Regul. 28:194-202.

Faggian, R., Bulman, S. R., Lawrie, A. C., and Porter, I. J. 1999. Specific polymerase chain reaction primers for the detection of Plasmodiophora brassicae in soil and water. Phytopathology 89:392-397.

Fritzinger, D. C., Petrella, E. C., Connelly, M. B., Bredehorst, R., and Vogel, C. W. 1992. Primary structure of cobra complement component C3. J. Immunol. 149:3554-3562.

Ito, S., Maehara, T., and Tanaka, S. 1997. Cloning of a single-copy DNA sequence unique to Plasmodiophora brassicae. Physiol. Mol. Plant Pathol. 50:289-300.

Ji, R., Zhao, L., Xing, M., Shen, X., Bi, Q., Peng, S., and Feng, H. 2014. Infection of Plasmodiophora brassicae in Chinese cabbage. Genet. Mol. Res. 13:10976-10982.

Klewer, A., Luerûen, H., Graf, H., and Siemens, J. 2001. Restriction fragment length polymorphism markers to characterize Plasmodiophora brassicae singlespore isolates with different virulence patterns. J. Phytopathol. 149:121-127.

Kuginuki, Y., Yoshikawa, H., and Hirai, M. 1999. Variation in virulence of Plasmodiophora brassicae in Japan tested with clubroot-resistant cultivars of Chinese cabbage (Brassica rapa L. ssp. pekinensis). Eur. J. Plant Pathol. 105:327-332.

Manzanares-Dauleux, M. J., Barret, P., and Thomas, G. 2000. Development of a pathotype specific SCAR marker in Plasmodiophora brassicae. Eur. J. Plant Pathol. 106:781-787.
Mehrabi, R., Bahkali, A. H., Abd-Elsalma, K. A., Moslem, M., M'Barek, S. B., Gohari, A. M., Jashni, M. K., Stergiopoulos, I., Kema, G. H., and de Wit, P. J. 2011. Horizontal gene and chromosome transfer in plant pathogenic fungi affecting host range. FEMS Microbiol. Rev. 35:542-554.

Möller, M., and Harling, R. 1996. Randomly amplified polymorphic DNA (RAPD) profiling of Plasmodiophora brassicae. Lett. Appl. Microbiol. 22: 70-75.

Ochman, H., Lawrence, J. G., and Groisman, E. 2000. Lateral gene transfer and the nature of bacterial innovation. Nature 405:299-304.

Richards, T. A., Hirt, R. P., Williams, B. A. P., and Embley, T. M. 2003. Horizontal gene transfer and the evolution of parasitic protozoa. Protist 154: 17-32.

Schwelm, A., Fogelqvist, J., Knaust, A., Jülke, S., Lilja, T., Bonilla-Rosso, G., Karlsson, M., Shevchenko, A., Dhandapani, V., Choi, S. R., Kim, H. G., Park, J. Y., Lim, Ludwig-Müller, J., and Dixelius, C. 2015. The Plasmodiophora brassicae genome reveals insights in its life cycle and ancestry of chitin synthases. Sci. Rep. 5: Article 11153.

Sharma, K., Gossen, B. D., and McDonald, M. R. 2011. Effect of temperature on cortical infection by Plasmodiophora brassicae and clubroot severity. Phytopathology 101:1424-1432.

Shen, X. Q., Nie, K., Wu, Q., Zhang, Y. G., and Meng, X. H. 2009. Initial research report on differentiation identification of Chinese cabbage clubroot main Physiological races. China vegetables. 2009(8):59-62.

Somé, A., Manzanares, M. J., Laurens, F., Baron, F., Thomas, G., and Rouxel, F. 1996. Variation for virulence on Brassica napus L. amongst Plasmodiophora brassicae collections from France and derived single-spore isolates. Plant Pathol. 45:432-439.

Sugai, R., Takemae, K., Tokuda, H., and Nishiyama, K. 2007. Topology inversion of SecG is essential for cytosolic SecA-dependent stimulation of protein translocation. J. Biol. Chem. 282:29540-29548.

White, S. H., Wimley, W. C., and Selsted, M. E. 1995. Structure, function, and membrane integration of defensins. Curr. Opin. Struct. Biol. 5:521-527.

Williams, P. H. 1966. A system for the determination of races of Plasmodiophora brassicae that infect cabbage and rutabaga. Phytopathology 56: 624-626.

Yano, S., Tanaka, S., Ito, S., and Kameya-Iwaki, M. 1997. Variations of random amplified polymorphic DNA (RAPD) patterns among field populations of Plasmodiophora brassicae. Ann. Phytopathol. Soc. Jpn. 63:179-182.

Zhang, H., Feng, J., Manolii, V. P., Strelkov, S. E., and Hwang, S. F. 2015. Characterization of a gene identified in pathotype 5 of the clubroot pathogen Plasmodiophora brassicae. Phytopathology 105:764-770. 